\title{
EXCIMER LASER USED AS A MATERIALS CHARACTERIZATION TOOL: SULPHIDE INCLUSION PRINTING IN STEEL
}

\author{
J. MCINTOSH*, A. ZERVAKI, K. PAPADIMITRIOU, \\ MIRTEC S.A., A' Industrial Area of Volos, GR-38500 Volos, Greece \\ *University of Illinois, Urbana, IL 61801 \\ G. N. HAIDEMENOPOULOS \\ University of Thessaly, GR-38334 Volos, Greece
}

\begin{abstract}
A. MANOUSAKI, G. ZERGIOTI, E. HONTZOPOULOS
FORTH-IESL, P.O. Box 1527, GR-711 10 Heraklio, Greece
\end{abstract}

(Received 5 September, 1992)

An application of the excimer laser in the area of material characterization making use of its ablative ability to perform surface sulphur printing is presented. It is shown that the differential ablative and surface melting capability of the excimer laser is useful in microetching sulphide inclusions in flat polished steel samples and rough fracture surfaces.

An optimum laser fluence is found to be that which melts the sulphide particles without significant melting of the steel matrix or causing overlap of the characteristic halo formed by the out-flowing liquid from the sulphides.

The geometric similarity of the sulphide inclusions is maintained and its spatial extent is amplified about 10 times. This brings sub-micron sulphide particles into optical resolution range.

The liquid wetting behavior of the sulphide liquid is variable with $\mathrm{Mn} / \mathrm{Fe}$ ratio and determines the extent of the halo formation.

KEY WORDS: Excimer laser, sulphide printing, fracture surface, material characterization

\section{INTRODUCTION}

In most cases sulphur is not desirable in steels. It forms a brittle low melting point Iron sulphide that greatly weakens and embrittles the steel.

However, sulphur is deliberately added in a controlled manner to a class of steels called "free-machining". This is in order to take advantage of the fact that the brittle sulphides in the microstructure cause the machine turnings to break into short chips. This allows production speed to be considerably increased.

In such steels Iron is partly replaced with elements that preferentially form sulphides of higher melting point, low surface tension and of controlled shape. 
Manganese and Calcium are the most common of these added elements used for inclusion shape control.

Thus there is a need for metallurgists to be able to observe the distribution of sulphides in steels. There is a classic chemical method known commonly as "sulphur printing" . ${ }^{1}$ According to this method a smoothly ground steel surface is moistened with a chemical that reacts with the sulphides which then release a plume of gas. A sheet of photographic paper is placed over the surface and the evolved gas reacts with it and locally darkens the paper providing a print of the sulphide distribution. The chemical reactions during sulphur printing are as follows:

$$
\begin{gathered}
\underset{\text { Fe, Mn, }+\ldots) \mathrm{S}}{\text { sulphide inclusion }}+\underset{\text { reactant }}{\mathrm{H}_{2} \mathrm{SO}_{4}} \rightarrow \mathrm{H}_{2} \mathrm{~S} \uparrow+\text { other products } \\
\mathrm{H}_{2} \mathrm{~S} \uparrow+\underset{\text { emulsion }}{2 \mathrm{AgBr}} \rightarrow \underset{\text { Dark area on print }}{\mathrm{Ag}_{2} \mathrm{~S} \downarrow+2 \mathrm{HBr}}
\end{gathered}
$$

The gas plume and resulting darkening on the print acts to magnify the spatial extent of the sulphide inclusion.

However, this method fails in the case of a rough fracture surface. But this is exactly the surface that is of most interest for use in failure analysis. The liberated $\mathrm{H}_{2} \mathrm{~S}$ gas becomes trapped in the rough fracture surfaces not sealed by the covering photographic paper, losing spatial correspondence of the sulphide. At the moment there is no acceptable method available for printing rough surfaces. In addition there are a number of cases where the classical sulphur print method fails to give an acceptable intensity in highly alloyed steels or non-ferrous systems. ${ }^{1}$

A recent paper $^{2}$ demonstrated the successful ablative action of the excimer laser on sulphide inclusions in steel. It was then decided to confirm that observation and extend the method to rough fracture surfaces.

The relatively low power and non-thermal nature of the ultraviolet excimer laser restricts its use towards material processing. But it is exactly this property that makes it useful in materials characterization. Specifically it is the ablative ability that we make use of here by supplying a large energy density with a short pulse duration. The effect of the excimer pulse is to preferentially melt the sulphide inclusion and for the resulting liquid to flow out from and around the inclusion. This greatly magnifies the area of the inclusion while maintaining its geometric similarity. The surrounding steel microstructure is slightly geometrically affected, i.e. the sharp edges have been rounded. The net result is a magnification and enhancement of the position and distribution of the sulphides or other inclusions and thus the formation of a chemical print. This print contains information originating from shape and spatial position as well as chemical information from relative melting-point and liquid surface tension.

\section{EXPERIMENTAL}

Specimens for analysis were obtained from a free-machining type of steel forming a bearing race. Two types of specimens were prepared from the longitudinal section 
of the bearing race. The first one was a metallographic section. The second was a fracture surface obtained by shock fracturing in bending.

The chemical composition of the steel is $0.06 \mathrm{wt} \% \mathrm{C}, 0.27 \mathrm{wt} \% \mathrm{~S}$ and $1.34 \mathrm{wt} \% \mathrm{Mn}$. Thus the expected sulphide would be an Iron-Manganese type sulphide with a melting point higher than that of a pure Iron sulphide. In addition, the liquid surface energy would be reduced compared to a pure Iron-sulphide leading to comparatively reduced wetting characteristics sought from sulphides in free-machining steels. The manganese acts to reduce grain boundary wetting and embrittlement by the brittle sulphide at low temperatures. ${ }^{3}$

An excimer laser of the LPX 200 type operating at $248 \mathrm{~nm}(\mathrm{KrF})$ delivering up to $0.4 \mathrm{~J}$ per pulse in a pulse length of 29 nanoseconds was employed for sulphide melting and ablation. A line focus of gaussian profile intensity was formed by a cylindrical lens. The power density employed ranged from zero to $200 \mathrm{MW} / \mathrm{cm}^{2}$ as controlled by overfocussing the laser on the specimen surface. A parallel series of non-overlapping, line-focus spots, formed from a single pulse, were laid down on the specimens with increasing steps of $50 \mathrm{MW} / \mathrm{cm}^{2}$. The excimer laser treatment was made in air.

\section{RESULTS}

The excimer laser treated surfaces were examined by SEM and qualitative EDX chemical analysis was performed. Untreated specimens that were diamond polished revealed sulphide inclusions of an approximate oval shape containing Iron, Manganese and Sulphur. Only the largest of sulphide inclusions were detectable in the fracture surface, usually at the site of a cup-cone fracture where it had acted as a stress-raiser. Laser irradiation with a power density of $50 \mathrm{MW} / \mathrm{cm}^{2}$ resulted in little change in the sulphide inclusion shapes except for a slight halo of disturbed material surrounding them as a kind of "foot print" indicating an inclusion. At 100 and 150 $\mathrm{MW} / \mathrm{cm}^{2}$ the sulphide inclusions had a strongly contrasting halo of at least 10 times the original diameter or the width of the sulphide inclusions (see Figure 1).

Sulphides of sub-micron size were brought into strong contrast due to the magnifying effect of the halo foot print (see Figure 2). A fracture surface irradiated with a fluence of $100 \mathrm{MW} / \mathrm{cm}^{2}$ is seen in Figure 3. The largest sulphide particles can be seen lying in the bottom of cups acting as crack stress raisers in the surrounding matrix. Although here the density of sulphide particles is high, even the smallest submicron sulphides have been printed with a characteristic halo.

At power densities of $200 \mathrm{MW} / \mathrm{cm}^{2}$ the halo foot prints had become so large and diffuse that they were no longer at optimum contrast and frequently overlapped. At high magnification the sulphide particles were seen to be cracked and partially separated from the matrix. EDX analysis of the resulting halo footprints showed them to have a slight $\mathrm{Mn}$ and $\mathrm{S}$ enrichment above the average matrix values. This is assumed to be an indication that the material in this region, although most likely to be ablated from the $\mathrm{Mn}$ and $\mathrm{S}$ rich inclusions, is actually quite thin and contributes little volume fraction to the EDX probe. 


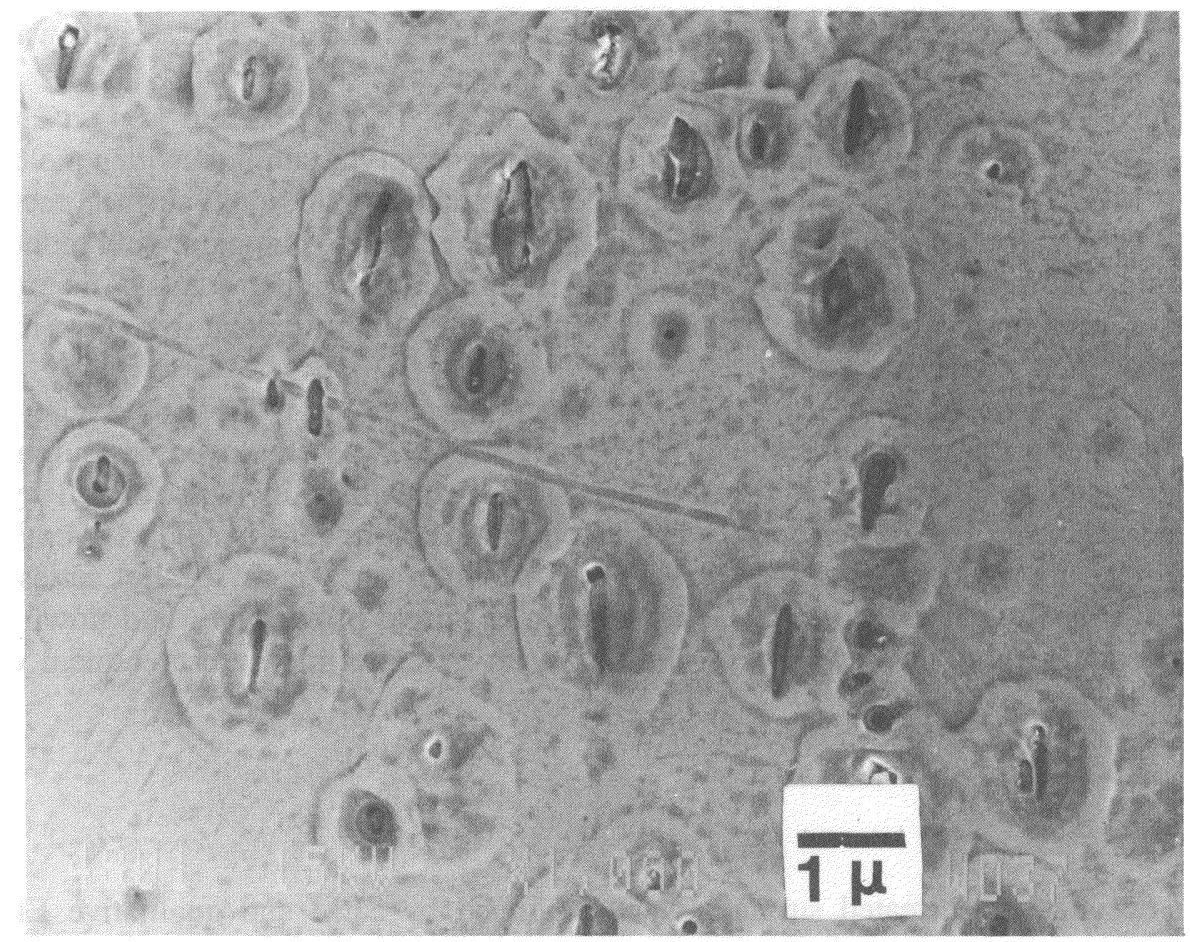

Figure 1 SEM micrograph showing sulphide inclusions surrounded by characteristic halo-footprints. The surface was irradiated by excimer laser, $248 \mathrm{~nm}(\mathrm{KrF})$ operating at $150 \mathrm{MW} / \mathrm{cm}^{2}$ power density. $\mathrm{EDX} \mathrm{Mn} / \mathrm{Fe}$ peak ratio $=3$.

\section{DISCUSSION}

The observed alteration of the sulphide inclusions by excimer laser treatment resulted in a halo-footprint of strong contrast and increased diameter with respect to the inclusion diameter. In both the polished and rough fracture surface the result was to magnify the presence of these inclusions, particularly the smallest.

The proposed mechanism for this is as follows. The sulphide and the surrounding steel matrix are heated by the UV pulse. The steel is not melted at the $50-150 \mathrm{MW} / \mathrm{cm}^{2}$ power density but the sulphides are. Thus the liquid sulphide is first ejected by the acoustical pressure pulse out of the sulphide inclusion where it subsequently flows into a smooth circular region by liquid surface tension, where it freezes into place.

This mechanism suggests that the size of the halo foot-print should depend both on the sulphide melting point and surface tension, both of which are related to chemical properties of the particular phase or inclusion. In the inclusion under consideration this would be the manganese content. In support of the above assumption, that the steel is not melted at these low power densities, the results of a relevant calculation 


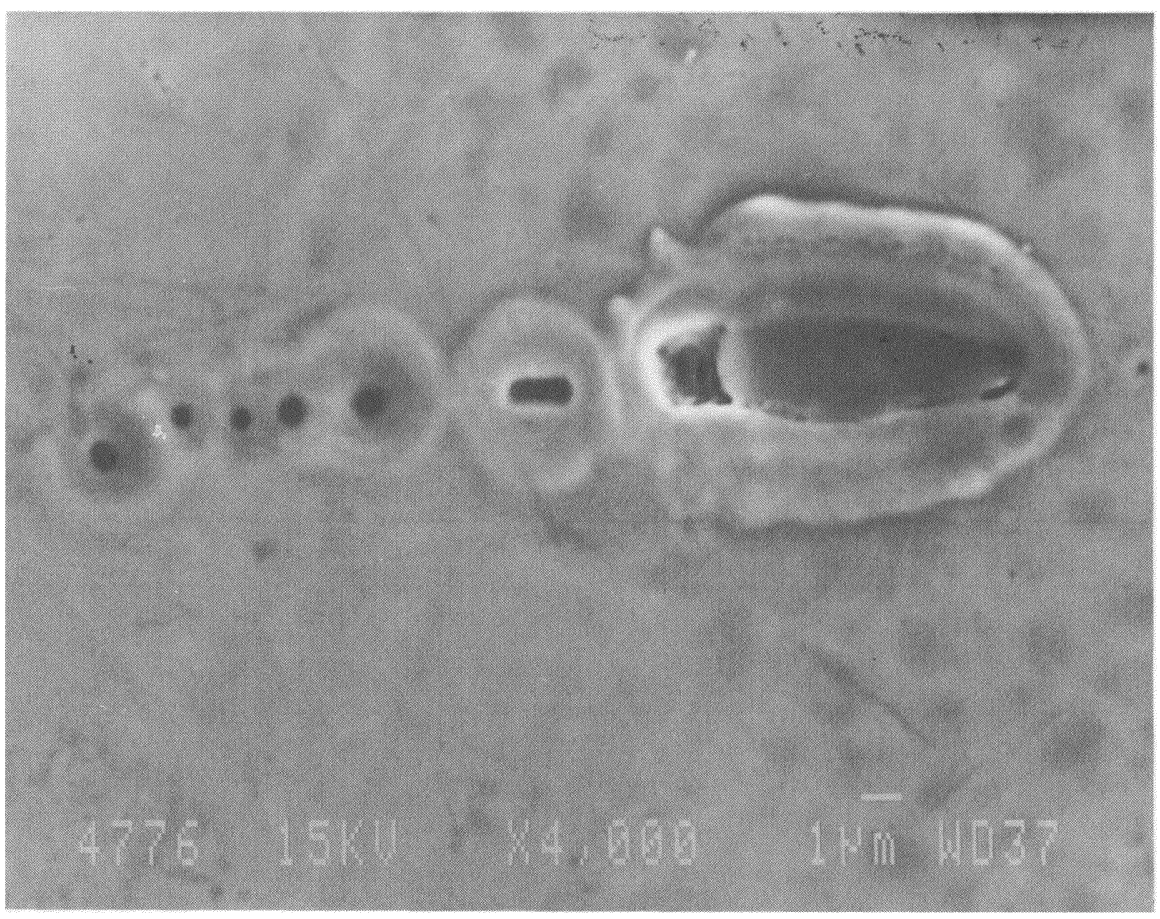

Figure 2 SEM micrograph showing sub-micron sulphide particles in fine detail trailing behind large sulphide particle at right. The surface was irradiated by a $248 \mathrm{~nm}(\mathrm{KrF})$ excimer laser operating at $150 \mathrm{MW} / \mathrm{cm}^{2}$ power density. EDX $\mathrm{Mn} / \mathrm{Fe}$ peak ratio $=3$.

from reference 4 are stated. According to this calculation, the intensity required to cause melting of a typical steel surface by excimer irradiation is greater than $280 \mathrm{MW} / \mathrm{cm}^{2}$. This is sufficiently greater than the intensities used in this work. In addition the heat penetration depth $\mathrm{D}$, taken as an extremely stringent indication of the heat affected zone can be calculated as $D=(4 \mathrm{kt})^{1 / 2}$ where $K$ is the thermal diffusitivity of steel taken equal to $0.077 \mathrm{~cm}^{2} \mathrm{sec}^{-1},{ }^{4}$ and $\mathrm{t}$ is time in seconds of the pulse length taken to be $29 \mathrm{~ns}$. Here $\mathrm{D}<0.96 \mu \mathrm{m}$, suggesting that the heat affected zone must be quite small. This demonstrates the surface effect of this technique.

The results of the magnification of the inclusion size by the formation of a liquid halo-footprint is similar to dye penetrant crack detection. In that technique a crack which is too small to be observed optically is made visible by allowing an absorbed dye to flow out of the crack and into a covering liquid developer forming a similarly magnified halo.

\section{Extension of Excimer Chemical Printing}

Further extensions of the excimer chemical printing technique can be considered. Another as of yet unexplored area is to apply an active element by evaporation or 


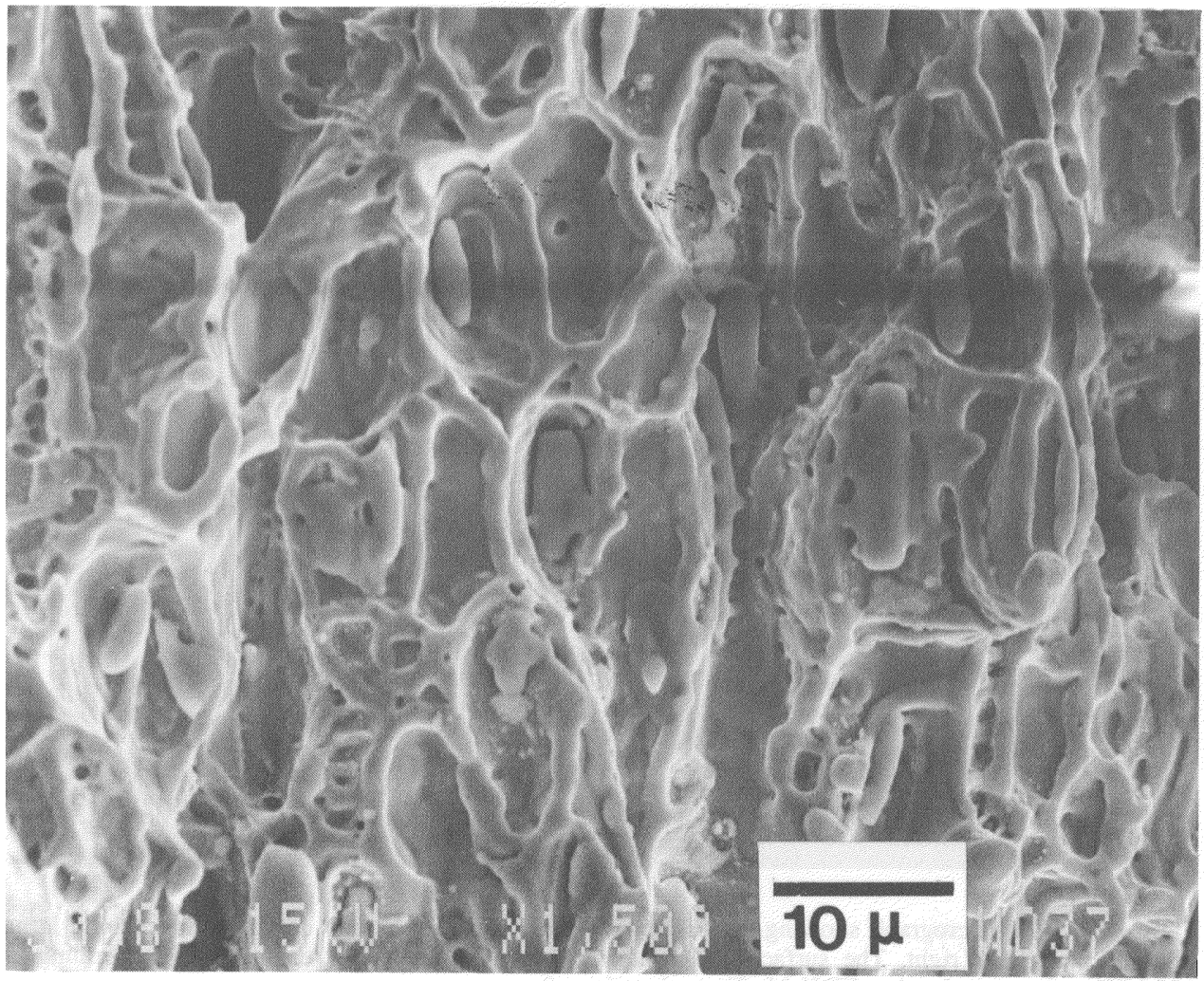

Figure 3 SEM micrograph of a fracture surface irradiated by a $248 \mathrm{~nm}(\mathrm{KrF})$ excimer laser operating at $100 \mathrm{MW} / \mathrm{cm}^{2}$ power density. Note that even the smallest sulphides have been printed with a characteristic halo shape. The sulphides in this fracture surface are of a higher EDX peak Mn/Fe ratio (12) than that described in the text and seen in Figures 1 and 2.

sputtering onto the surface to be examined before excimer irradiation. The film thickness should be on the order of $0.1 \mu \mathrm{m}$ thickness. This element could be a metal such as $\mathrm{Al}$ or $\mathrm{Au}$ with a known tendency to form low melting-point eutectic systems. This active layer could then be used to lower the melting point of certain segregated regions, precipitates or microstructural features that would not ordinarily be different enough from the matrix or each other to yield a useful excimer laser print. This active layer would form a low melting point liquid that is required for excimer chemical printing.

Of greatest interest would be applications where classical chemical etching rate differences do not allow the formation of high contrast images with good spatial resolution. 


\section{CONCLUSIONS}

The excimer laser sulphur print technique is capable of forming a high contrast sulphur print with spatial amplification of at least ten at an optimum power density of $100-150 \mathrm{MW} / \mathrm{cm}^{2}$ in the case of steel. This technique is capable of being used on both smooth and rough surfaces as found in fracture surfaces. The spatial magnification brings this technique into the optical image resolution range for even the finest of sulphide inclusions.

The effect of alloy content on the surface energy and wetting properties of the melted sulphide inclusions is observed in the extent of spreading of the halo formation following laser irradiation (see Figure 4).

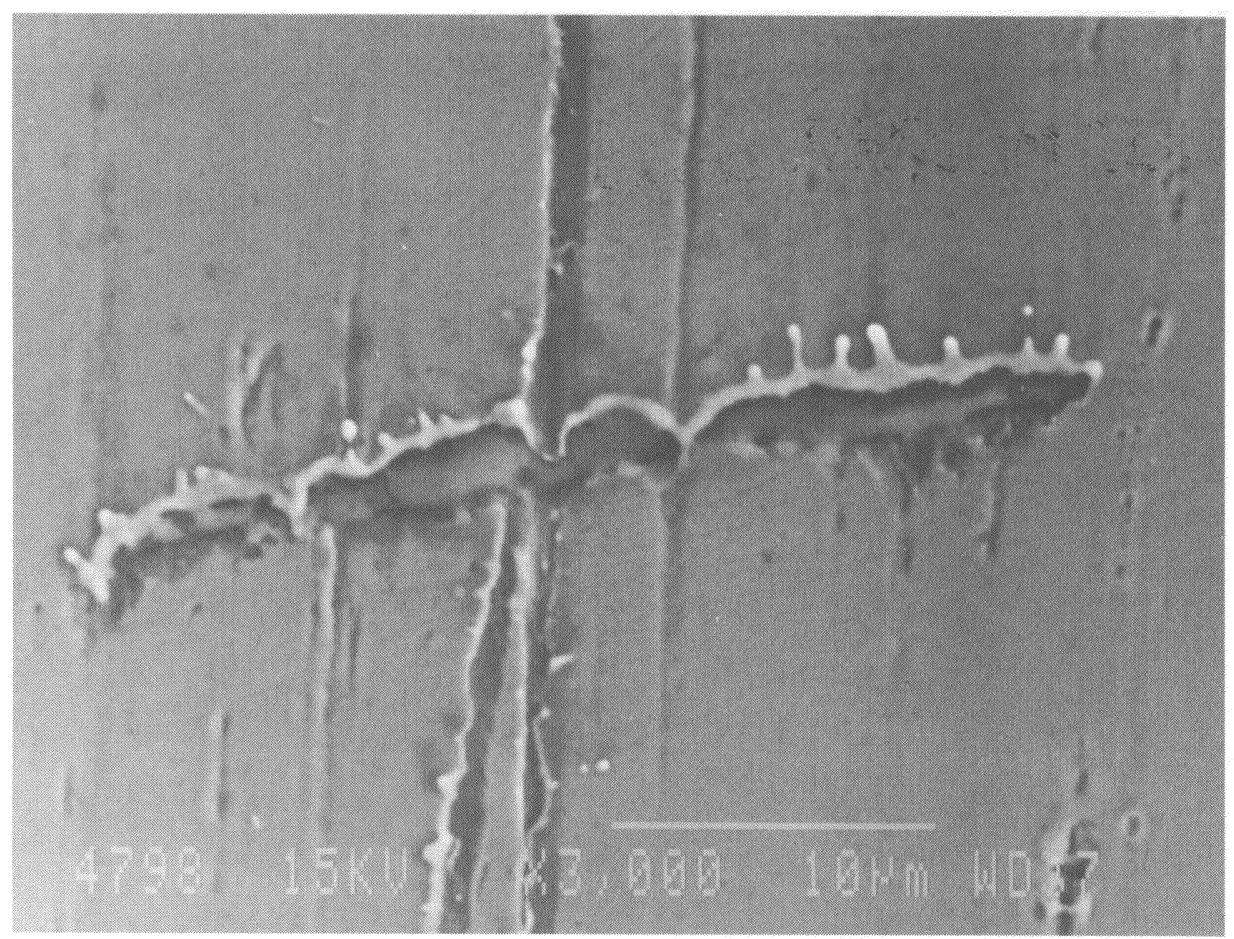

Figure 4 SEM micrograph showing melting of sulphide inclusion at $100 \mathrm{MW} / \mathrm{cm}^{2}$ power density. Note frozen droplets. This sample was chosen to demonstrate the effect of different chemical content of the sulphides on surface energy. It had sulphides of a higher EDX Mn/Fe peak ratio (12) than that described in the text and seen in Figures 1 and 2. Note that the melted sulphide did not wet the steel surface. This is expected from the higher $\mathrm{Mn} / \mathrm{Fe}$ ratio. 
The technique of excimer chemical printing looks promising for applications in both ferrous and non-ferrous inclusion printing. It's strength appears to be the ability to identify sub-micron or sub-surface inclusions with high spatial resolution as well as qualitative indications of liquid surface energy of melted inclusions over large areas of observation.

The possibility of extending the technique to include pre-placed, eutectic forming thin films as a material characterization tool is suggested for future work.

\section{References}

1. G. Vander Voort, Metallography, McGraw-Hill Series in Material Science.

2. F. G. Shin, P. W. Chan, W. L. Tsui, K. W. Wong. J. Mat. Science Let., 9, 216 (1990).

3. V. Kajanpaa, Hot Cracking of Sulphide Shape Controlled High machinable Steel Welds, JDC University Research Symposium, Toronto, Ontario, Canada, October 1985.

4. S. Altshulin, J. Zahavi, A. Rosen. J. Mat. Science, 25, 2259 (1990). 